\title{
The effectiveness of Japanese sandals use on lower leg function among elderly women living in the community
}

\author{
Mizue Hiura*, Kazuko Nishisaka, Kiyomi Higashi, Chiharu Matsumoto \\ Department of Community Health Nursing, Faculty of Life Sciences, Kumamoto University, Kumamoto, Japan; \\ "Corresponding Author: mizueh@kumamoto-u.ac.jp
}

Received 6 September 2013; revised 18 October 2013; accepted 25 October 2013

Copyright (C) 2013 Mizue Hiura et al. This is an open access article distributed under the Creative Commons Attribution License, which permits unrestricted use, distribution, and reproduction in any medium, provided the original work is properly cited.

\begin{abstract}
The aim of this study was to investigate the efficacy of specially designed zori, a Japanese-style sandal, for enhancing walking performance. A total of 89 women aged 59 - 75 were randomly assigned to either the intervention or control group. The intervention group wore the zori for 6 months while the control group did not. We conducted physical assessments, including The Good Walker's Index, which consisted of a 10-m walking time measurement, maximal step length, the $40 / 20-\mathrm{cm}$ step test and tandem gait, and measurement of the toe-gap force (TGF). Additionally, bare foot plantar pressure distribution was measured using a foot-mapping sensor, while gait characteristics were measured using three dimensional sensors. In the intervention group, means for TGF improved significantly between baseline and three months and between baseline and six months, but this improvement was not evident in the control group. In the intervention group, the means for pressure and surface areas of both left and right feet significantly decreased over time compared with the control group. Three-dimensional analysis found that left and right ankle height was enhanced in the intervention group, and their walking speed was improved by the extension of their stride length and an increase in the height of the tiptoe in one cycle. The findings in our study indicate that zori can be useful in improving lower leg function through TGF enhancement and adjustment of the pressure pattern.
\end{abstract}

Keywords: Japanese Elderly; Footwear; Toe-Gap Force; Planter Pressure Distribution

\section{INTRODUCTION}

The ability to walk efficiently is very important for older people in terms of helping to reduce the risk of falling and allowing them to live as independently as possible within the community. Many associations between aging and mobility performance $[1,2]$ have been recognized, and various risk factors for falls, such as female gender, poor balance, muscle weakness, decline in reaction time, cognitive impairment, the taking of medication, and environmental factors, have been identified $[3,4]$. Floating toes [5], decline in movement adjustments [6] and walking balance [7] have also been reported as risk factors for falls.

To maintain walking ability in old age, studies have reported the effectiveness of regular physical activity [1, 8] and programs of regular physical exercise such as those to improve balance and muscle strength training [9]. The effectiveness of interventions with home exercise [10], water-based exercise [11], balance improvement through the use of video game exercises [12], and Tai Chi Quan training [13] for older populations has also been studied. However, it is not easy for older adults, who only have limited opportunities for exercise or even activities outside the home, to maintain physical activity on a daily basis.

Several studies have focused on footwear as an inexpensive and accessible intervention. These studies have reported the effect of an insole on postural stability [14], reductions in postural sway while wearing sandals [15], and insoles with a textured pattern for young participants in a quiet stance [16]. However, there has been limited research concerning the association between footwear and walking ability among older people living in the community.

In Japan, zoris (Japanese-style sandals) were traditionally worn by older people, particularly during the summer season. One study has reported improvements in 
floating toe in a Japanese population that wore zori [17]. The zoris in our study are designed such that they do not restrict the movement of the phalanx of the toe, and they are hypothesized to enhance the toe-gap force (TGF), the muscular force between the first and second toes. TGF is used as a measure of lower limb muscular strength and propulsive gait. Associations of lower limb muscular strength with balance, general mobility, and falls have been reported $[2,18]$.

The aim of this study is to examine the efficacy of a specially designed zori, worn on a daily basis for enhancing walking performance, including TGF.

\section{METHODS}

\subsection{Participants}

A total of 89 women aged $59-75$ volunteered to be study participants. We choose female participants because females have a higher overall risk of falls [19] and a greater number of women showed interest in joining this study. All the participants were living independently in the same city, in the south of Japan, with a population of approximately 27,000 people, where females aged 59 - 75 make up $25.9 \%$ of the population. Participants were excluded if they had neurological diseases, cognitive impairments, vision problems or had experienced a fall within the last year.

All participants were given written consent forms and were insured before any physical tests were taken. This study was approved by the Kumamoto University Ethics Committee.

\subsection{Trial Design}

Participants were initially screened by phone for eligibility, and randomly assigned to either the intervention group or control group before the baseline assessment was conducted. The intervention group was asked to wear zori for 6 months while the control group did not wear zori. The intervention group underwent physiological and walking ability tests at 0,3 and 6 months, and the control group took the same tests at 0 and 6 months.

Participants in the intervention group were given two pairs of zori, one for indoor and one for outdoor use. The zori were made from polypropylene/rayon material and an ethylene-vinyl acetate (EVA) sole with an EVA/cotton strap, which separates the toes (Homare Co., Ltd, Tokyo, Japan). The height of the sole is $22.5 \mathrm{~mm}$ and the zori have been designed so that the foremost portion of the insole is lower to enhance TGF.

\section{DATA COLLECTION}

\subsection{Measurements}

Each participant completed a questionnaire that in- cluded information on their demographic characteristics, instrumental daily living (IADL), whether or not they were consulting a doctor, medication, and their subjecttive well-being.

The Trail Making Test (TMT) is a widely used test that evaluates the cognitive domains of executive function and it consists of two parts (TMT A and B) $[20,21]$. The Japanese version has also been used for evaluating cognitive function $[22,23]$. For TMT A, participants have to connect the numbers from 1 to 25 . For TMT B, participants have to connect spaced numbers from 1 to 13 , and Japanese letters in alternating numeric and Japanese syllabary order. TMT performance was recorded using time to completion, with errors being pointed out by the examiner and included in the total time. We employ a difference score (TMT B-A) calculated by subtracting TMT A from TMT B [24].

The physical assessment was conducted at a local community hall. There was sufficient space for the circuit assessment, with assistants, including a physician, provided for participants' safety. Height and weight were measured using electric scales without shoes and with any heavy clothing removed, and the Body Mass Index $\left(\mathrm{BMI}=\right.$ weight $/$ height $\left.^{2}\right)$ was calculated. Blood pressure (systolic and diastolic) was checked by a physician and a determination was made concerning whether or not a participant was able to undertake further physical assessment tasks.

The Good Walker's Index was used to assess physicological performance [25]. This index consists of four tests: a 10-m walking time measurement, maximal step length (MSL), the 40/20-cm step test, and tandem gait. The tests were rated on a 5-point Likert scale (with 5 the highest and 1 the lowest), and the scores were adjusted for age and gender.

The 10-m walking time measures the time taken by the participant to walk as quickly as possible over a $10-\mathrm{m}$ distance. MSL measures the maximum length of the individual's stride for each step. For the 20/40-cm step test, the participants were asked to step up and down on a 20or $40-\mathrm{cm}$ ladder according to their level of ability. For tandem gait, the participants were asked to walk a maximum of 10 steps in which the toe of the back foot touches the heel of the front foot for each step.

TGF is the pressure between the first and second toes, and was measured using a Checker-Kun (Nissin Sangyo Co., Saitama, Japan). Both sides of each leg were measured twice, and the highest value was taken.

Barefoot plantar pressure distribution was measured using the EPS Platform (LorAn Engineering, Bologna, Italy). The platform allows for static and dynamic analysis and assesses the movement of the body's center of gravity under different conditions. Participants were asked to step on the platform. The pressure between the 
ground and the plantar surface of the foot was measured while participants were standing and while walking. The two-step method, in which plantar pressures are obtained on the second step, was used, and has proven to be a valid method for obtaining reliable pressure data with the least amount of repeated trials [26]. The plantar pressure distribution, peak plantar pressure and center of pressure were recorded with specific software (Footchecker version 4.0; LorAn Engineering).

The dynamic plantar pressure footprints generated by the participants were recorded. The mean peak pressure footprints were analyzed to determine the peak pressure (Kpa; the highest pressure value recorded by a sensor) and pressure time integral (Kpa s; the integral of pressure over time). The $\mathrm{L}$ and $\mathrm{R}$ surface area were measured as the contact area between the foot and floor.

The presence of floating toes was identified by analyzing participants' footprints while walking. We used a floating toes count [17] that scored each toe as a grounded toe ( 2 points), partially ungrounded toe ( 1 point), and non-grounded toe ( 0 points), with a possible total of 20 points for both feet. In cases where no floating toe was present, 20 points were scored.

Spatiotemporal gait characteristics were measured using a BTS SMART-D (BTS Bioengineering), which is capable of multi-factorial analysis with highly sensitive three dimensional sensors. Participants were asked to attach point sensors to both sides of their body at nine points (knee, external malleolus, heel, metatarsal bone V, great trochanter, acromion, elbow, wrist, fingertip), and walk on a treadmill for a total of 3 minutes including the trial measurement. They were instructed to "walk at a comfortable pace," with their pace adjusted on the treadmill. The data were recorded for 10 seconds during stable walking time. The pitch (steps/minute) and stride length $(\mathrm{cm})$, stride width $(\mathrm{cm})$, swing phase, and angle of the toe (in/out) were assessed.

Average stride length was measured by summing right step length and left step length, and average stride width was measured as the distance between the $L$ and the $R$ foot while walking. Ankle height while walking was measured as the highest point the ankle was lifted to minus the landing point.

\subsection{Statistical Analysis}

Comparisons between the intervention and control group were determined using an independent samples t-test for continuous variables (age, BMI) and a MannWhitney test for variables with non-normal distribution, with a chi-squared test used for categorical data.

Physical assessment data from the evaluation points were missing for seven subjects in the intervention group and five subjects in the control group. There were physiccal test analyses for a total of 77 participants. The
Friedman test and Wilcoxon signed-rank test were used to compare variables at different time points.

A two-way repeated-measures ANOVA followed by Bonferroni adjustment examined whether the two groups differed in terms of improvement on the physical tests between the baseline assessment and six months later. A p-value of $<0.05$ was considered to indicate statistical significance, and all tests were two-tailed. Statistical analysis was undertaken using SPSS version 19 and R version 2.13.0 [27].

\section{RESULTS}

\subsection{Characteristics of the Study Population}

The 89 participants were aged from 59 to 75 (mean age $67.1 \pm 3.5$ ), and their BMI and blood pressure measurements were within normal levels according to Japanese guidelines [28,29].

It has been reported that TMT B-A declines with age, and compared with a study of elderly Japanese [23], our subjects showed similar results.

There were no significant differences between the two groups regarding age, BMI, TMT B-A, blood pressure and IADL score. There were also no significant differences between the groups in the four tests of the Good Walker's Index. Thus, participants in each of the two groups had similar baseline characteristics and were considered to be independent and active populations (Table 1).

\subsection{Physical Tests}

Comparing TGF at the baseline and the 6 month follow-up between the two groups, significant interactions (group $\times$ time) were found for both left $(\mathrm{L})$ and right $(\mathrm{R})$ TGF (L: $F=11.17, p<0.005 ; R: F=11.57, p<0.005)$. The TGF means at baseline, and three- and six-month follow-up periods are shown in Figure 1. In the zori intervention group, the TGF means improved as time progressed. There were significant differences between baseline and three months (TGF L p $<0.001$, TGF R p $<$ 0.01 ) and between baseline and 6 months (TGF L p < 0.01 , TGF $\mathrm{R} \mathrm{p}<0.05)$. No significant change was found in the control group.

Table 2 shows the means and standard deviations of the foot mapping sensor measurements. Significant interactions (group $\times$ time) were found for both $\mathrm{L}$ and $\mathrm{R}$ pressures (L: $F=7.56, p<0.01 ; R: F=6.36, p<0.05$ ). In the intervention group, the mean pressure of both the $\mathrm{L}$ and $\mathrm{R}$ foot decreased over time compared with the control group. The $\mathrm{L}$ and $\mathrm{R}$ surface areas in the intervention group improved at a different rate to that of the controls over time, with the surface areas of both feet significantly decreasing in the intervention group (L: F = 8.57, $\mathrm{p}<0.01, \mathrm{R}: \mathrm{F}=6.0, \mathrm{p}<0.05)$. 
Table1. Demographic characteristics.

\begin{tabular}{|c|c|c|c|c|c|}
\hline & & Total $(\mathrm{n}=89)$ & Zori $(n=44)$ & Control $(n=45)$ & $\mathrm{p}$ \\
\hline \multicolumn{2}{|c|}{ Age $(59-75)$} & $67.1 \pm 3.5$ & $67.5 \pm 3.6$ & $66.8 \pm 3.5$ & 0.31 \\
\hline \multicolumn{2}{|c|}{ BMI \# } & $23.1 \pm 2.7$ & $23.3 \pm 2.8$ & $22.8 \pm 2.6$ & 0.39 \\
\hline \multicolumn{2}{|c|}{ TMTB-A } & $59.2 \pm 46.1$ & $58.3 \pm 32.8$ & $58.3 \pm 56.5$ & 0.47 \\
\hline \multicolumn{2}{|c|}{ IADL score $^{\dagger}$} & $8.0 \pm 0.2$ & $8.0 \pm 0.2$ & $8.0 \pm 0.2$ & 0.98 \\
\hline \multicolumn{2}{|c|}{ Systolic Blood Pressure } & $131.1 \pm 12.9$ & $128.9 \pm 11.6$ & $133.1 \pm 13.9$ & 0.19 \\
\hline \multicolumn{2}{|c|}{ Diastolic Blood Pressure } & $72.5 \pm 10.4$ & $73.7 \pm 11.3$ & $73.1 \pm 10.8$ & 0.45 \\
\hline \multicolumn{2}{|c|}{ Maximal step length $\mathrm{R}$} & $4.09 \pm 1.01$ & $4.27 \pm 0.86$ & $4.33 \pm 0.73$ & 0.13 \\
\hline \multicolumn{2}{|c|}{ Maximal step length L } & $3.93 \pm 1.02$ & $3.80 \pm 1.07$ & $4.07 \pm 0.96$ & 0.22 \\
\hline \multirow{2}{*}{$\begin{array}{l}\text { Walker’s } \\
\text { Index }{ }^{\ddagger}\end{array}$} & alking time & $3.92 \pm 0.88$ & $3.93 \pm 0.93$ & $3.91 \pm 0.79$ & 0.65 \\
\hline & step test & $4.90 \pm 0.34$ & $4.91 \pm 0.36$ & $4.89 \pm 0.32$ & 0.51 \\
\hline \multicolumn{2}{|c|}{ Tandem gait } & $4.82 \pm 0.58$ & $4.82 \pm 0.58$ & $4.82 \pm 0.58$ & 0.97 \\
\hline \multirow{2}{*}{$\begin{array}{l}\text { Living conditions } \\
\text { (\%) }\end{array}$} & With others & $71(79.8)$ & $34(38.2)$ & 37 (41.6) & \multirow{2}{*}{0.61} \\
\hline & Alone & $18(20.2)$ & $10(11.2)$ & $8(9.0)$ & \\
\hline \multirow{2}{*}{$\begin{array}{c}\text { Seeing } \\
\text { a doctor }(\%)\end{array}$} & Yes & $66(74.2)$ & $32(36.0)$ & $34(38.2)$ & \multirow{2}{*}{0.81} \\
\hline & No & $23(25.8)$ & $12(13.5)$ & $11(12.4)$ & \\
\hline \multirow{2}{*}{ Medication (\%) } & Taking & $62(69.7)$ & $30(33.7)$ & $32(36.0)$ & \multirow{2}{*}{0.76} \\
\hline & None & $27(30.3)$ & $14(15.7)$ & $13(14.6)$ & \\
\hline
\end{tabular}

Note: "BMI: weight/height. 'IADL: Eight items included using a telephone, shopping, preparing food, housekeeping, doing laundry, using transportation, handling medications and finances. A high score shows a high level of independence. "Good Walker's Index consists of maximal step length, 10 -m walking time, 20/40 step test and tandem gait. These were rated on a 5-point Likert scale (5 highest, 1 lowest).

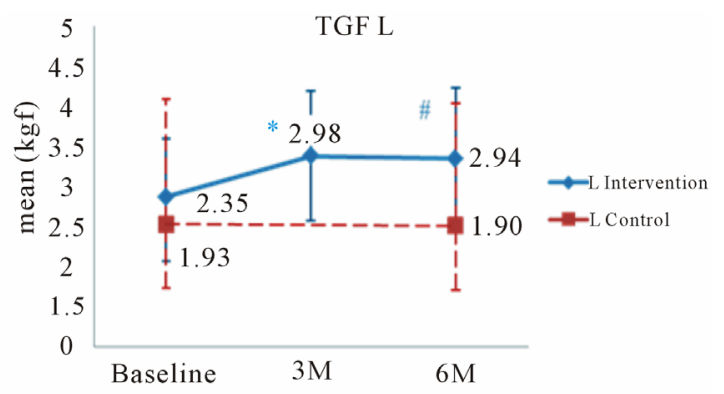

TGF R

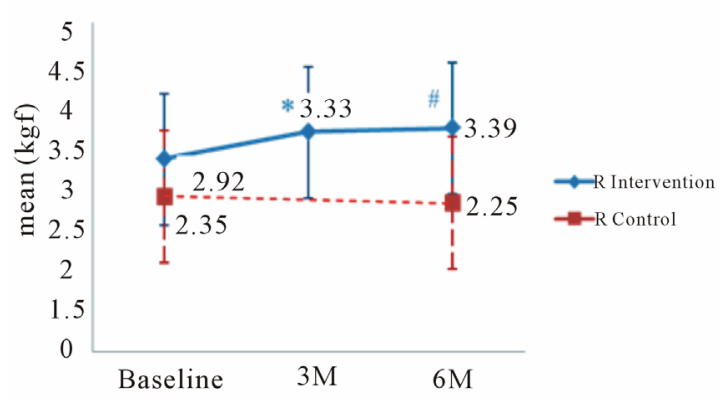

Figure 1. Means \pm standard deviation of left and right toe-gap force. Indicates a significant difference between baseline and 3 months; "\#ndicates a significant difference between baseline and 6 months.
We employed the floating toe grouping [30] and categorized participants as having "normal" (both first toes grounded, a score of 2 , and a total $\geq 18$ score), "ungrounded toes" (11 - 17 score), or "floating toes" $(\leq 10)$. There were no cases of floating toes and only three cases of ungrounded toes among the 80 subjects. The mean of the floating toe score was $19.8 \pm 0.84$ (range $14-20$ ) at baseline. After 6 months, all three "ungrounded toes" cases in the intervention group showed improvement. There was no significant change in the floating toe scores between the two groups.

Table 3 shows the three-dimensional motion analysis at baseline and at the six-month follow-up period. L and $\mathrm{R}$ ankle height in the intervention group improved at a different rate to those in the control group over time, with $\mathrm{L}$ and $\mathrm{R}$ ankle height being enhanced in the intervention group. (Ankle $\mathrm{L}: \mathrm{F}=5.05, \mathrm{p}<0.05$; Ankle $\mathrm{R}: \mathrm{F}$ $=4.27, \mathrm{p}<0.05)$.

There was a significant time effect for Pitch L, Pitch R, average stride length, and average stride width. Those variables showed improvement after six months (Pitch L: $\mathrm{F}=24.89, \mathrm{p}<0.001$; Pitch R: F26.26, $\mathrm{p}<0.001$; average stride length, $\mathrm{F}=16.23, \mathrm{p}<0.001$; average stride width, $\mathrm{F}=29.90, \mathrm{p}<0.001$ ); however, there were no interacttions or significant differences between groups. 
Table 2. Foot mapping sensor measurements at baseline and at 6 months.

\begin{tabular}{lcccccc}
\hline & \multicolumn{2}{c}{ Zori $(\mathrm{n}=37)$} & \multicolumn{2}{c}{ Control $(\mathrm{n}=40)$} & $\mathrm{F}$ & $\mathrm{p}$ \\
\hline & Baseline & 6 months & Baseline & 6 months & & \\
& $42.8 \pm 8.87$ & $32.2 \pm 11.0$ & $41.0 \pm 7.00$ & $35.6 \pm 9.36$ & 7.56 & $<0.01$ \\
Pressure (L foot) Kpa(r) & $42.8 \pm 8.12$ & $32.3 \pm 9.05$ & $42.2 \pm 7.50$ & $36.0 \pm 10.19$ & 6.36 & $<0.05$ \\
Pressure (R foot) Kpa(r) & $99.5 \pm 11.73$ & $74.3 \pm 11.37$ & $100.2 \pm 10.53$ & $86.2 \pm 25.94$ & 8.57 & $<0.01$ \\
Surface Area (L foot) $\mathrm{cm}^{2}$ & $99.7 \pm 10.17$ & $85.1 \pm 11.55$ & $102.6 \pm 11.11$ & $96.2 \pm 24.25$ & 6.00 & $<0.05$ \\
Surface Area (R foot) $\mathrm{cm}^{2}$ & &
\end{tabular}

Surface area: The contact area between the foot and floor. Interaction of time of assessment and group based on results from a two-way repeated-measures ANOVA adjusted for multiple comparisons using the Bonferroni correction. Mean \pm standard deviation.

Table 3. Three-dimensional motion analysis at baseline and at 6 months.

\begin{tabular}{ccccccc}
\hline & \multicolumn{2}{c}{ Zori $(\mathrm{n}=32)$} & \multicolumn{2}{c}{ Control $(\mathrm{n}=36)$} & $\mathrm{F}$ & \\
\hline & Baseline & 6 months & Baseline & 6 months & & \\
Pitch L (Steps/ minute) & $67.2 \pm 7.01$ & $62.6 \pm 5.57$ & $66.4 \pm 7.26$ & $62.6 \pm 10.00$ & 0.22 & 0.64 \\
Pitch R (Steps/ minute) & $67.2 \pm 7.00$ & $62.5 \pm 5.55$ & $66.5 \pm 7.27$ & $62.5 \pm 10.00$ & 0.18 & 0.67 \\
Average stride length (L and R step length) & $40.5 \pm 11.57$ & $44.5 \pm 11.78$ & $43.6 \pm 13.52$ & $47.8 \pm 18.17$ & 0.00 & 0.96 \\
Average stride width & $21.2 \pm 4.83$ & $23.5 \pm 5.20$ & $22.8 \pm 6.32$ & $24.3 \pm 7.00$ & 1.7 & 0.20 \\
Ankle L & $16.5 \pm 4.75$ & $21.7 \pm 6.40$ & $17.2 \pm 4.08$ & $16.0 \pm 5.12$ & 34.26 & $<0.01$ \\
Ankle R & $16.8 \pm 5.40$ & $22.4 \pm 6.71$ & $17.3 \pm 4.41$ & $16.6 \pm 6.23$ & 27.99 & $<0.01$ \\
\hline
\end{tabular}

Pitch: Number of steps/minute. Average stride length: Average of (L step length $+\mathrm{R}$ step length); Average stride width: Average of (the distance between $\mathrm{L}$ and $\mathrm{R}$ foot); Ankle L and R: Average of (the highest point-landing point) when walking; Interaction of time of assessment and group based on results from a twoway repeated-measures ANOVA adjusted for multiple comparisons using the Bonferroni correction. Mean \pm standard deviation.

\section{DISCUSSION}

TGF has been identified as an effective measurement of lower limb muscular strength and as important for propulsive gait $[31,32]$. There was a significant improvement of both $\mathrm{L}$ and $\mathrm{R}$ TGF over time for the intervention group.

The zori used in this study were designed with a lower foot bed at the tip of the toes that can provide support to enhance the strength between the big and little toes. Studies have reported on the effectiveness of habitual exercise in improving TGF in children [33] and the effectiveness of toe-gap/planter flexion exercise for stability and physical movement in adults [34]. Older participants in our study showed significant improvement in TGF. They wore zori for 6 months and the self-reported average length of time for wearing zori was $26.3 \pm 21.4$ hours/week (range: 2.1 - 77.0). This suggests that wearing zori in their daily life enhanced the lower muscular strength of our participants via improved TGF.

The toes are in contact for about three quarters of the walking cycle, and play an important part in increasing the weight-bearing area while walking [35], holding the ground during anterior movement and striking the ground while walking [36]. Toes can enlarge the weightbearing area so that when the heel is raised, full bodyweight is not taken on the metatarsal heads alone [35]. Some studies have reported a relationship between floating toe and a backward center of gravity and kinetic balance $[6,17]$.

Our results showed that $28.8 \%$ of the participants ( 23 out of the 80 analyzable cases) had some form of partially ungrounded toes, but were still considered "normal" (scored $\geq 18$ ). Three cases were categorized as "ungrounded" and there were no cases of "floating toes" among our participants. Tuneya et al. reported that $66 \%$ of male and $76.2 \%$ of female Japanese adults had ungrounded toes, mostly occurring on the fifth toe. The elderly shift their weight forward as they age, and there may have a lower incidence of floating toe when compared with younger adults [36].

However, our results are unable to support the notion that zori may improve floating toe, because there was no significant difference between the intervention and control group. The surface areas of the $\mathrm{L}$ and $\mathrm{R}$ foot were reduced, and this can be explained by the appearance of a plantar arch and greater uniformity of pressure as the reduction of surface area was not brought about by floating toes.

Kerstin and colleagues [37] studied the pressure patterns in different generations and reported that foot loading in older people showed a higher peak pressure and longer contact time when compared with younger adults.

The results from the foot-mapping sensor in our study showed that the $\mathrm{L}$ and $\mathrm{R}$ pressures, and the surface area, decreased over time. This resultant pressure reduction means that the pressure is spread evenly and more equally distributed over the entire foot. Considering the influence of body weight on peak pressure, it has been reported that there is no significant correlation between weight and peak pressure [37], and it was also suggested 
that the influence of weight could be considered for obese or overweight subjects [38]. There were no obese individuals among our subjects, and we did not see a correlation between BMI and pressure in our study.

Participants' walking speed was improved by extending their stride length and increasing the height of the tiptoe over one cycle. Both intervention and control groups exhibited an extension of $\mathrm{L}$ and $\mathrm{R}$ stride lengths and reduced steps per minute after 6 months. The average heel height was also significantly increased. It can be surmised that the participants tended to walk with longer steps and higher stepping after 6 months. However, except for the average heel height, there were no statistical differences between the two groups.

We speculate that during the trial, the control group also might have worn summer sandals that are similar to zori. Furthermore, the control group comprised quite an active population, so they may have performed extra physical activity that our study could not account for.

Additionally, there are some limitations to be considered. Participants were asked to wear the zori for 6 months. However, we cannot be certain of the precise length of time the participants wore the zori. Further study is needed in a larger sample of older participants to confirm our findings for generalization, and to evaluate the influence of their own footwear in daily use.

\section{CONCLUSIONS}

The findings of our study indicate that zori can be useful in enhancing the function of the toes through enhancing TGF, and adjusting the pressure pattern as a result of broadening the pressure area.

Some improvements were found in both groups. Our participants were under the age of 75 and they appeared to be quite an active population. They seemed to enjoy physical activity, and those factors could have influenced the data; thus, future analysis is needed to identify the degree of improvement.

Zori is easy to be incorporated into daily life in Asian cultures, although the amount of use is influenced by the seasons. Many studies [4,39] recommend an exercise program for maintaining physical functions and fall prevention; however, some older people do not have easy access to care prevention services or regular exercise because of their physical condition or surroundings. The low persistence rate of exercise owing to a lack of adherence has been discussed. Zoris can be easily brought into people's daily lives, and they can thus serve as an effective tool for maintaining lower leg function and help to contribute to fall prevention.

\section{ACKNOWLEDGEMENTS}

We are grateful to the participants who voluntarily took part to make this study possible. We acknowledge "Homare Co., Ltd, Tokyo, Japan" for supporting the footwear and insurance for participants and helping with the measuring instruments in this study. We thank Prof. Takahiko Katou, Department of Public Health, Faculty of Life Sciences, Kumamoto University for comments and suggestions on preparing the manuscript.

\section{REFERENCES}

[1] Visser, M., Pluijm, S.M.F., Stel, V.S., Bosscher, R.J. and Deeg, D.J.H. (2002) Physical activity as a determinant of change in mobility performance: The longitudinal aging study Amsterdam. Journal of the American Geriatrics Society, 50, 1774-1781.

http://dx.doi.org/10.1046/j.1532-5415.2002.50504.x

[2] Kuruganti, U. (2006) Strength and muscle coactivation in older adults after lower limb strength training. International journal of industrial ergonomics, 36, 761-766. http://dx.doi.org/10.1016/j.ergon.2006.05.006

[3] Yoshida, S. (2007) A global report on falls prevention, epidemiology of falls. Ageing and Life Course, Family and Community Health, WHO.

[4] Karlsson, M.K. (2013) Prevention of falls in the elderly-A review. Osteoporosis International, 24, 747-762. http://dx.doi.org/10.1007/s00198-012-2256-7

[5] Hiramatu, T., Izumi, K., Kato, M. and Shogenji, M. (2005) Prevention of falls in community-dwelling elderly: The relation among contact surface of toes, foot sole, functional ability and fall. Journal of Japan Academy of Gerontological Nursing, 9, 116-123.

[6] Fukuyama, K., Osanai, M. and Maruyama, H. (2009) Adult toe contact and the function of floating toes. Rigakuryoho kagaku, 24, 683-687. http://dx.doi.org/10.1589/rika.24.683

[7] Hasegawa, M., Shimatani, K., Kanai, S., Oki, S., Shimizu, M.E., Muguruma, A., et al. (2010) The effect on gait of the lack of ground connection by the toes in standing. Rigakuryoho kagaku, 25, 437-441. http://dx.doi.org/10.1589/rika.25.437

[8] Chang, M. (2013) Midlife physical activity preserves lower extremity function in older adults: Age gene/environment susceptibility-Reykjavik study. Journal of the American Geriatrics Society (JAGS), 61, 237-242. http://dx.doi.org/10.1111/jgs.12077

[9] Karinkanta, S., Heinonen, A., Sievanen, H., Uusi-Rasi, K., Pasanen, M., Ojala, K., et al. (2007) A multi-component exercise regimen to prevent functional decline and bone fragility in home-dwelling elderly women: Randomized controlled trial. Osteoporosis International, 18, 453-462. http://dx.doi.org/10.1007/s00198-006-0256-1

[10] Niemela, K. (2011) Benefits of home-based rocking-chair exercise for physical performance in community-dwelling elderly women: A randomized controlled trial. Aging clinical and experimental research, 23, 279-287.

[11] Hale, L.A. (2012) A randomized controlled trial to investigate the effects of water-based exercise to improve falls risk and physical function in older adults with lower-extremity osteoarthritis. Archives of Physical Medicine and Rehabilitation, 93, 27-34. http://dx.doi.org/10.1016/j.apmr.2011.08.004 
[12] Lamoth, C.J.C. (2011) Exergaming improves dynamic balance in community dwelling elderly. Assistive technology research series, 29, 818-824.

[13] Wolf, S.L. (1997) The effect of Tai Chi Quan and computerized balance training on postural stability in older subjects. Physical Therapy, 77, 371-384.

[14] Qiu, F. (2012) Enhanced somatosensory information decreases postural sway in older people. Gait \& posture, 35, 630-635. http://dx.doi.org/10.1016/j.gaitpost.2011.12.013

[15] Palluel, E. (2009) The lasting effects of spike insoles on postural control in the elderly. Behavioral neuroscience, 123, 1141-1147. http://dx.doi.org/10.1037/a0017115

[16] Corbin, D.M. (2008) The effect of textured insoles on postural control in double and single limb stances. Journal of sport rehabilitation, 17, 20.

[17] Yahagi, T., Nemoto, M. and Fukuyama, K. (2004) Utilizing a zouri to treat a floating toe and ease low back pain. Kutunoigaku, 18, 65-71.

[18] Lord, S.R. and Sturnieks, D.L. (2005) The physiology of falling: Assessment and prevention strategies for older people. Journal of Science and Medicine in Sport, 8, 35-42. http://dx.doi.org/10.1016/S1440-2440(05)80022-2

[19] Stalenhoef, P.A., Diederiks, J.P.M., Knottnerus, J.A., Kester, A.D.M. and Crebolder, H.F.J.M. (2002) A risk model for the prediction of recurrent falls in community-dwelling elderly: A prospective cohort study. Journal of Clinical Epidemiology, 55, 1088-1094. http://dx.doi.org/10.1016/S0895-4356(02)00502-4

[20] Hobert, M.A., Niebler, R., Meyer, S.I., Brockmann, K., Becker, C. and Huber, H. (2011) Poor trail making test performance is directly associated with altered dual task prioritization in the elderly-baseline results from the trend study, 6, Article ID: e27831.

[21] Lowry, K.A., Brach, J.S., Nebes, R.D., Studenski, S.A. and Vanswearingen, J.M. (2012) Contributions of cognitive function to straight- and curved-path walking in older adults. Archives of Physical Medicine and Rehabilitation, 93, 802-807.

http://dx.doi.org/10.1016/j.apmr.2011.12.007

[22] Hasegawa, C. and Hirono, N. (2011) Trail Making Test (TMT) A and B (Ninchisyougaku, Jyou-Kan). The Japanese Journal of Clinical Medicine, 69, 423-427.

[23] Hirota, C., Watanabe, M., Tanimoto, Y., Kono, R., Higuchi, Y. and Kono, K. (2011) A cross-sectional study on the relationship between the Trail Making test and mobilityrelated functions in community-dwelling elderly. The Journal of Osaka Medical College, 70, 39-47.

[24] Corrigan, J.D. and Hinkeldey, N.S. (1987) Relationships between parts A and B of the Trail Making test. Journal of Clinical Psychology, 43, 402-409. http://dx.doi.org/10.1002/1097-4679(198707)43:4<402:: AID-JCLP2270430411>3.0.CO;2-E

[25] Okada, S., Takahashi, R. and Takahashi, M. (2004) Good walker's Index Jissen Handbook. 2 Edition, Physical Education and Medicine Research Foundation, Nagano.

[26] Bus, S.A. and Lange, A.D. (2005) A comparison of the 1-step, 2-step, and 3-step protocols for obtaining barefoot plantar pressure data in the diabetic neuropathic foot.
Clinical Biomechanics, 20, 892-899.

http://dx.doi.org/10.1016/j.clinbiomech.2005.05.004

[27] Kanda, Y. (2012) Investigation of the freely available easy-to-use software "EZR" for medical statistics. Bone Marrow Transplantation, 48, 452-458. http://dx.doi.org/10.1038/bmt.2012.244

[28] Mori, M., Shimomura, I., Kadowaki, T. and Hosoda, K. (2011) Consideration on Diagnostic criteria of obesity and morbid obesity in Japan. Journal of Japan Society for the Study of Obesity, 17, 143-144.

[29] The Japanese Society of Hypertension (2009) Guidelines for the management of hypertension 2009. Life Science Publishing Co. Ltd., Japan.

[30] Fukuyama, K. and Maruyama, H. (2012) The determination of floating toes and the reliability of its assessment. Rigakuryoho kagaku, 27, 497-502. http://dx.doi.org/10.1589/rika.27.497

[31] Yamashita, K., Iwakami, Y., Imaizumi, K., Sato, M., Nakashima, S., Ino, S., et al. (2010) Development of screening method for a frail elderly by measurement quantitative lower limb muscular strength. The transactions of the Institute of Electrical Engineers of Japan. C, A publication of electronics. Information and System Society, 130, 2210-2218. http://dx.doi.org/10.1541/ieejeiss.130.2210

[32] Nomoto, Y., Yamashita, K., Ohya, T., Koyama, H. and Kawasumi, M. (2010) Development of evaluation methods for lower limb function between aged and young using principal component analysis. The transactions of the Institute of Electrical Engineers of Japan. C, A publication of electronics. Information and System Society, 130, 370-375. http://dx.doi.org/10.1541/ieejeiss. 130.370

[33] Yamashita, K. (2012) Development of measurement devices for quantitative evaluation of lower limb muscle strength on children. Transaction of Japanese Society for Medical and Biological Engineering, 50, 1-11.

[34] Kito, N., Ihara, H., Miwa, M., Kouya, H., Shimazawa, S., Baba, Y., et al. (2001) Effects of toe motion exercise to prevent falls in the elderly. Rigakuryoho kagaku, 28, 313319.

[35] Hughes, J. (1990) The importance of the toes in walking. Journal of Bone and Joint Surgery, British Volume, 72, 245-251.

[36] Tuneya, M. and Usui, N. (2006) Actual state of toe contact in the upright position among healthy adults. The Journal of Japanese Physical Therapy Association, 33, 30-37.

[37] Kerstin, B., Arne, N., Lars, W. and Dieter, R. (2009) From "first" to "last" steps in life-Pressure patterns of three generations. Clinical Biomechanics, 24, 676-681. http://dx.doi.org/10.1016/j.clinbiomech.2009.06.001

[38] Mickle, K.J., Steele, J.R. and Munro, B.J. (2006) Does excess mass affect plantar pressure in young children? International Journal of Pediatric Obesity, 1, 183-188. http://dx.doi.org/10.1080/17477160600881734

[39] Baker, M.K. (2007) Multi-modal exercise programs for older adults. Age and Ageing, 36, 375-381. http://dx.doi.org/10.1093/ageing/afm054 